\title{
New sex dependent normal limits of the signal averaged electrocardiogram
}

\author{
Ten-Fang Yang, Peter W Macfarlane
}

\begin{abstract}
Background-An earlier study of 1555 normal 12 lead electrocardiograms has shown that the mean QRS duration in men is $8 \mathrm{~ms}$ longer than in women.

Objective-To establish the sex related normal limits of the signal averaged electrocardiogram.
\end{abstract}

People-195 people (160 men and 35 women aged 40 to 69) with normal clinical history, physical examination, 12 lead electrocardiogram, and echocardiogram were recruited for this study.

Methods-Signal averaged electrocardiograms were recorded by the Arrhythmia Research Technology 1200 EPX machine and analysed twice with bidirectional Butterworth filters with frequency ranges of 25-250 $\mathrm{Hz}$ and 40-250 $\mathrm{Hz}$. Three time domain parameters of the QRS vector magnitude, namely filtered total QRS duration, duration of low amplitude signals under $40 \mu \mathrm{V}$ (LAS40), and root mean square voltage of the last $\mathbf{4 0} \mathrm{ms}$ (RMS40), were evaluated.

Results-There were significant differences between the two sexes in QRS duration (mean $(95 \%$ confidence interval $(95 \% \mathrm{CI}))(8.0(3.1$ to 13.0$) \mathrm{ms}, t=3.29$, degrees of freedom $=41, p=0.0021$ with the 25-250Hz filter; mean (95\% CI) $10 \cdot 2$ (6.9 to 13.5$) \mathrm{ms}, t=6.26$, degrees of free$\operatorname{dom}=53, p<0.0001$ with the $40-250 \mathrm{~Hz}$ filter)) and in body surface area (mean (95\% CI) $0.26(0.21$ to 0.31$) \mathrm{m}^{2}, t=10.63$, degrees of freedom $=57$ ). There was no significant correlation between age and QRS duration, LAS40, or RMS40, but there was a highly significant correlation between body surface area and QRS duration (correlation coefficient $=0.396$, $p<0.0005$ ) and RMS40 (correlation coefficient $=-0 \cdot 159, p<0 \cdot 025)$. Current sex independent criteria defining ventricular late potentials as the presence of any two of QRS duration $>114 \mathrm{~ms}$, LAS40 $>38 \mathrm{~ms}$, RMS40 $<20 \mu \mathrm{V}$, give a specificity of $85 \%$ for men and $91 \%$ for women in this normal population.

Recommendations-Ventricular late potentials should be regarded as present when $(a)$ QRS duration exceeds $114 \mathrm{~ms}$ in men or $104 \mathrm{~ms}$ in women and (b) either LAS40 $>38 \mathrm{~ms}$ or RMS40 $<20 \mu \mathrm{V}$. This gives a specificity of $97 \%$ in men and $100 \%$ in women in the population studied.

(Br Heart F 1994;72:197-200)
The presence of ventricular late potentials has been associated with an arrhythmogenic substrate characterised by fragmented electrical activity due to delayed ventricular activation and slowed propagation of conduction in the myocardium, which in turn seems to be related to the development of ventricular arrhythmias. ${ }^{1}$ The signal averaged electrocardiogram has been used to detect ventricular late potentials in order to select patients at risk of future arrhythmic events on account of their underlying clinical problem-for example, recent myocardial infarction, ${ }^{2}$ hypertrophic cardiomyopathy, ${ }^{3}$ etc. The incidence of ventricular late potentials is reported to be from $0-7 \%$ in normal people without sustained ventricular tachycardia, ${ }^{4}$-that is, present criteria have a specificity of $93 \%-100 \%$. Late potentials occur in $20 \%$ of patients with structurally normal hearts and sustained ventricular tachycardia. ${ }^{5}$ A European and North American task force recently suggested guidelines for defining the presence of ventricular late potentials, ${ }^{6}$ but these were not sex dependent.

Our previous studies of the normal 12 lead electrocardiograms of 1330 healthy people, ${ }^{7}$ recently extended to 1555 healthy volunteers, have shown that the mean QRS duration in men is $8 \mathrm{~ms}$ longer than in women (table 1). Therefore it was thought necessary to establish sex related normal limits of the signal averaged electrocardiogram.

\section{Methods}

195 people ( 160 men and 35 women, aged 40 to 69 , table 2) with normal clinical history, physical examination, 12 lead electrocardiogram, and echocardiogram were recruited for our study. They were all employees of the local regional council and were mainly in sedentary occupations.

Signal averaged $\mathrm{X}, \mathrm{Y}, \mathrm{Z}$ leads were

Table 1 Age and sex related normal limits of $Q R S$ duration (ms) in 1555 white people

\begin{tabular}{lcc}
\hline Age & Men & Women \\
\hline 18-29: & & \\
Mean (SD) & $95(10)$ & $85(8)$ \\
Range (96th percentile) & $78-112$ & $68-106$ \\
No & 242 & 304 \\
30-39: & $94(10)$ & $87(7)$ \\
Mean (SD) & $76-116$ & $72-100$ \\
Range (96th percentile) & 217 & 131 \\
No & $93(10)$ & $86(8)$ \\
40-49: & $76-112$ & $72-102$ \\
Mean (SD) & 97 \\
Range (96th percentile) & 210 & \\
No & $93(10)$ & $85(8)$ \\
50+: & $74-114$ & $70-102$ \\
Mean (SD) & 139 \\
Range (96th percentile) & 215 & \\
No & & \\
\hline
\end{tabular}


Table 2 Age and sex distribution of the apparently healthy people studied

\begin{tabular}{lccclc}
\hline Age & $40-44$ & $45-49$ & $50-54$ & $55+$ & Total \\
\hline Men & 47 & 41 & 43 & 29 & 160 \\
Women & 7 & 6 & 7 & 15 & 35 \\
Total & 54 & 47 & 50 & 44 & 195 \\
\hline
\end{tabular}

recorded according to the recommendations of the Task Force of the European Society of Cardiology (ESC), the American Heart Association (AHA), and the American College of Cardiology (ACC) ${ }^{6}$ The signal averaged electrocardiograms were recorded with the Arrhythmia Research Technology 1200 EPX machine. Data were recorded by temporal averaging of the amplified signal to a noise level of less than $1.0 \mu \mathrm{V}$ and transferred to a central computer. Later the same data were retrieved for analysis with the personal computer version of the Arrhythmia Research Technology analysis software (version $4 \cdot 0$ ). Filtering was by bidirectional Butterworth filters with frequency ranges of $25-250 \mathrm{~Hz}$ and $40-250 \mathrm{~Hz}$ to avoid filter artefact or ringing.

Three parameters of the QRS vector magnitude were evaluated: filtered total QRS duration; duration of low amplitude signals $<40 \mu \mathrm{V}$ (LAS 40); root mean square voltage of the terminal $40 \mathrm{~ms}$ (RMS 40).

Body surface area (BSA) was derived from the height $(\mathrm{H})$ and mass $(\mathrm{M})$ of each person by the formula of Du Bois and Du Bois ${ }^{8}$ :

$\operatorname{BSA}\left(\mathrm{cm}^{2}\right)=\mathrm{M}(\mathrm{kg})^{0.425} \times \mathrm{H}(\mathrm{cm})^{0.725} \times 71.84$

The two sample Student's $t$ test was used to evaluate the significance of the sex differences in QRS duration, LAS40, and body surface area, whereas the Mann-Whitney non-parametric test was used for RMS40, which was not normally distributed. The 96 th percentile ranges of these three parameters were determined by elimination of the extreme $2 \%$ of values at each end of the population distribution. This range almost coincides with that obtained from a mean (2 SDs) when a normal distribution is present. A p value $<0.05$ was regarded as significant. The Pearson's product moment correlation coefficient was measured between age and QRS duration, LAS40, and RMS40. The filtered QRS duration $(40-250 \mathrm{~Hz})$ was plotted as a percentage of people exceeding different values (fig 1).

\section{Results}

The QRS duration and LAS40 were normally

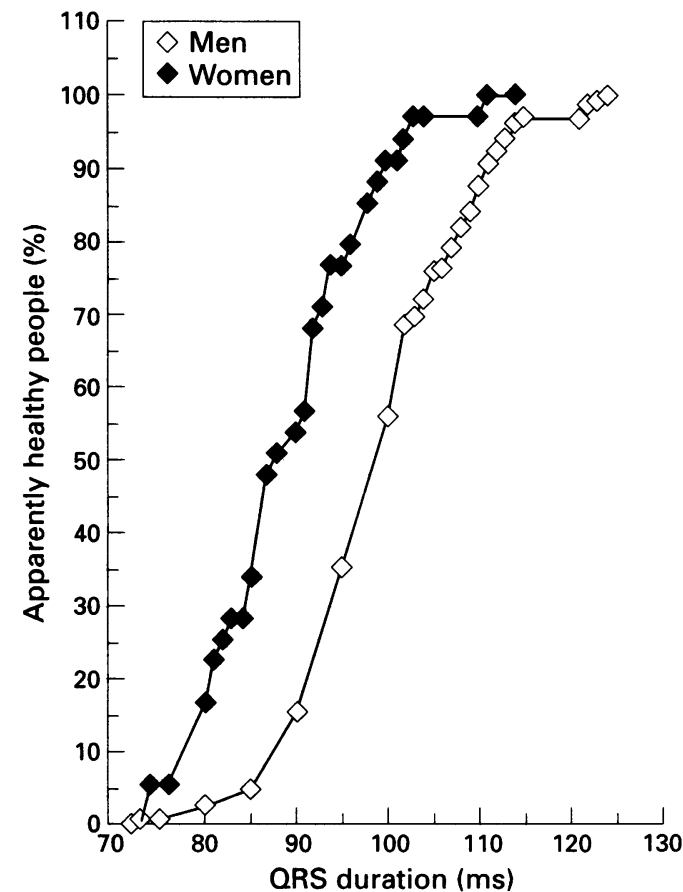

Figure 1 Cumulative distribution of filtered total $Q R S$ duration in apparently healthy people.

distributed, but not RMS40 (table 3 ). There were significant differences between the sexes only in QRS duration ( $\mathrm{p}=0.0021$ with the $25-250 \mathrm{~Hz}$ filter; $\mathrm{p}<0.0001$ with the $40-250 \mathrm{~Hz}$ filter) and in body surface area $(p<0.0001)$. The mean $(95 \%$ confidence interval (95\% CI)) difference in QRS duration between men and women was 8.0 (3.1 to $13.0) \mathrm{ms}$, at $25-250 \mathrm{~Hz}(t=3 \cdot 29$, degrees of freedom $=41)$, and $10.2(6.9$ to 13.5$) \mathrm{ms}$ at $40-250 \mathrm{~Hz}(t=6 \cdot 26$, degrees of freedom $=$ 53). The mean $(95 \% \mathrm{CI})$ difference in body surface area between the sexes was $0.26(0.21$ to 0.31$) \mathrm{m}^{2}(t=10.63, \mathrm{p}<0.0001$, degrees of freedom $=57$ ).

Current sex independent criteria-namely, (a) QRS duration $>114 \mathrm{~ms}$, (b) LAS $40>38$ ms, and (c) RMS $40<20 \mu \mathrm{V},{ }^{6}$ were individually moderately specific (table 4). Collectively, they define ventricular late potentials at $40-250 \mathrm{~Hz}$ as the presence of any two of a, b, and $c$, giving a specificity of $85 \%$ for men and $91 \%$ for women in the 195 apparently healthy people studied (table 4). The Pearson's product moment correlation coefficients between age and QRS duration, LAS40, and RMS40 were $-0.089,0.052$, and -0.012 , respectively ( $p>0 \cdot 1$, NS). Therefore, there was no significant correlation between age and these three

Table 4 Specificity of the individual components and combinations of the currently recommended AHA/ACC/ESC criteria $(40-250 \mathrm{~Hz})$

\begin{tabular}{llc}
\hline & $\begin{array}{c}\text { Men }(\%) \\
(n=160)\end{array}$ & $\begin{array}{c}\text { Women }(\%) \\
(n=35)\end{array}$ \\
\hline QRS duration >114 ms (a) & 96 & 100 \\
LAS40 $>38 \mathrm{~ms}(\mathrm{~b})$ & 83 & 91 \\
RMS40 $<20 \mu \mathrm{V}(\mathrm{c})$ & 79 & 86 \\
$\mathrm{a}+\mathrm{b}$ & 96 & 100 \\
$\mathrm{a}+\mathrm{c}$ & 97 & 100 \\
$\mathrm{~b}+\mathrm{c}$ & 85 & 91 \\
Any 2 of a, b, c & 85 & 91 \\
$\mathrm{a}+\mathrm{b}+\mathrm{c}$ & 97 & 100 \\
$\mathrm{a}+(\mathrm{b}$ or c) & 97 & 100 \\
\hline
\end{tabular}

\begin{tabular}{|c|c|c|c|c|}
\hline & \multicolumn{2}{|l|}{$25-250 \mathrm{~Hz}$} & \multicolumn{2}{|l|}{$40-250 \mathrm{~Hz}$} \\
\hline & Men & Women & Men & Women \\
\hline $\begin{array}{l}\text { QRS duration (ms): } \\
\text { Mean (SD) } \\
\text { Range (96th percentile) } \\
\text { LAS40 (ms): }\end{array}$ & $\begin{array}{l}102 \cdot 0(9 \cdot 4)^{*} \\
83-123\end{array}$ & $\begin{array}{l}94 \cdot 0(13 \cdot 8) \\
77-113\end{array}$ & $\begin{array}{l}99 \cdot 3(9 \cdot 4)^{\star} \\
80-122\end{array}$ & $\begin{array}{l}89 \cdot 1(8 \cdot 6) \\
74-103\end{array}$ \\
\hline $\begin{array}{l}\text { Mean (SD) } \\
\text { Range (96th percentile) }\end{array}$ & $\begin{array}{l}25 \cdot 7(9 \cdot 0) \\
11-45\end{array}$ & $\begin{array}{l}25 \cdot 1(9 \cdot 0) \\
11-43\end{array}$ & $\begin{array}{l}29 \cdot 8(9 \cdot 2) \\
12-49\end{array}$ & $\begin{array}{l}28 \cdot 5(8 \cdot 0) \\
17-44\end{array}$ \\
\hline $\begin{array}{l}\text { RMS40 ( } \mu \mathrm{V}): \\
\text { Mean (SD) } \\
\text { Range (96th percentile) }\end{array}$ & $\begin{array}{l}58 \cdot 1(39 \cdot 8) \\
13-174\end{array}$ & $\begin{array}{l}74 \cdot 1(44 \cdot 0) \\
18-153\end{array}$ & $\begin{array}{l}39 \cdot 3(26 \cdot 0) \\
9-103\end{array}$ & $\begin{array}{l}51 \cdot 2(36 \cdot 4) \\
11-151\end{array}$ \\
\hline
\end{tabular}

${ }^{\star} p=0.0021 ;{ }^{\star \star} p<0.0001$ between sexes. 
parameters, but there was a highly significant correlation between LAS40 and RMS40 (correlation coefficient $=-0.658, p<0.001)$ as well as between body surface area and QRS duration (correlation coefficient $=0.396, \mathrm{p}<$ 0.0005 , (fig 2)), and between body surface area and RMS40 (correlation coefficient = $-0.159, \mathrm{p}<0.025)$. We also found significant correlations between body surface area and body weight (correlation coefficient = $0.923, \mathrm{p}<0.0005$ ), age (correlation coefficient $=-0.224, \mathrm{p}<0.001)$, height $($ correlation coefficient $=0.744, \mathrm{p}<0.0005$ ), and sex (correlation coefficient $=-0.553, \mathrm{p}<0.0005)$. Figure 1 shows that the upper 95th percentile for a normal QRS duration was $114 \mathrm{~ms}$ in men and $104 \mathrm{~ms}$ in women.

\section{Discussion}

In recent years the technique of signal averaging in association with high gain amplification has been used to detect ventricular late potentials, which are high frequency low amplitude signals that occur in the terminal part of the QRS complex or ST segment. These late potentials have been postulated to be noninvasive markers of an arrhythmic substrate, which is characterised by slow non-homogeneous propagation of impulse conduction. ${ }^{126}$ There are many different approaches to the analysis of the signal averaged electrocardiogram. They can be categorised as time domain and frequency domain, including spectrotemporal ${ }^{9}$ and spectral turbulence ${ }^{10}$ analyses. Time domain analysis of the signal averaged electrocardiogram is usually performed by the method described by Simson in $1981 .^{2}$ In 1991, the ESC/AHA/ACC Task Force stated in their paper on standards for analysis of ventricular late potentials that although work is proceeding on frequency domain methods, there is a wide variety of

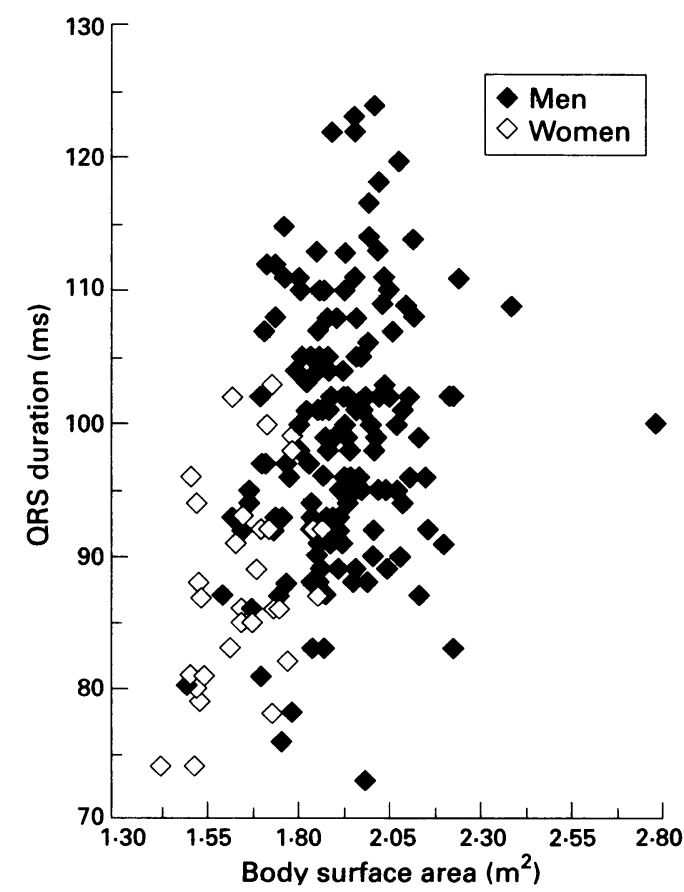

Figure 2 Scatter plot of the 40-250 Hz filtered $Q R S$ duration and the body surface area in apparently healthy people. algorithms available and no consensus that one method is better than the others. ${ }^{6}$ The review also suggested that selection of optimal methods and algorithms represents an area of current and future investigation. It still seems premature to standardise the various frequency domain approaches to the analysis of the signal averaged electrocardiogram. For these reasons, the current study has concentrated only on measuring the time domain parameters of the signal averaged electrocardiogram, commonly known as ventricular late potential analysis.

The ESC/AHA/ACC Task Force recommended that the analysis of ventricular late potentials in the time domain should include the parameters QRS duration, LAS40, and RMS40. ${ }^{6}$ However, their normal limits are critically dependent on the different recording and filtering techniques used in the various laboratories, and the different analysis software used. Most laboratories insist that the noise in the average beat is $<1 \mu \mathrm{V}$ and $<0.7$ $\mu \mathrm{V}$ for the $25 \mathrm{~Hz}$ and $40 \mathrm{~Hz}$ high pass bidirectional Butterworth filters, respectively, as recommended by the ESC/AHA/ACC Task Force,${ }^{6}$ whereas others seek to reduce noise to $<0.3 \mu \mathrm{V}$ for the $40 \mathrm{~Hz}$ high pass filter. Although signal averaging to the same specified residual noise level can minimise variation in the measurements of a signal averaged electrocardiogram, it is also problematic, because various devices define noise level differently. It cannot be assumed that if the same noise level is reported by instruments of different manufacture, the actual noise is the same. The final estimate of the noise level depends on factors such as the algorithm used for noise detection and calculation, the specific segment of the electrocardiogram examined, and the width of the interval scanned. ${ }^{11}$ It was also shown in the study by Engel et al that the residual noise can alter various measurements in the signal averaged electrocardiogram. ${ }^{11}$

Nevertheless, if the residual noise is consistently controlled to an equivalent and specified low level as recommended-that is, <0.7 $\mu \mathrm{V}$ for $40-250 \mathrm{~Hz}$ by the ESC/AHA/ACC Task Force, ${ }^{6}$ then this can produce excellent reproducibility. It is also recommended that the signal averaging process should be performed to a prespecified low residual noise level rather than being based on a set number of beats. ${ }^{12}$ The usefulness of a test depends on its reproducibility. There is some variation in the parameters of the signal average electrocardiogram, more so with spectral than with time domain measurements. The reproducibility of the frequency domain parameters is also problematic. ${ }^{11}$ The variation caused by differences in techniques for analysis, definition, and equipment can be overcome by standardisation to some extent, but, for example, standards for defining the end of the QRS complex are noise dependent and therefore open to variation.

Additional factors that should be taken into account in the causes of variation in detection of ventricular late potentials are age and sex. In 1985, Malik et al reported that in patients 
surviving myocardial infarction, QRS duration and LAS40 increase with age whereas RMS40 decreases with age. ${ }^{13}$ Thus they suggested that the criteria for the presence of ventricular late potentials should be age related. The difference between the two sexes, however, was not discussed.

In our study, no significant correlation was found between age and all three parameters in apparently healthy people. The age range of the people studied was from 40 to 69 , with similar numbers in each quintile up to 55 years (table 2). According to our earlier studies on the normal 12 lead electrocardiograms of 1555 volunteers, the mean QRS duration in men is $8 \mathrm{~ms}$ longer than in women but there was no strong trend with age (correlation coefficient: -0.077 in men, 0.005 in women). It was therefore not surprising that there was no correlation between age and QRS duration in this apparently healthy cohort. Thus the variation in QRS duration caused by sex differences was similarly found to be more important than that due to age, as in the signal averaged electrocardiogram. These findings relate specifically to adult electrocardiograms.

According to a necropsy study of the normal human heart by Kitzman et al, body mass and body surface area in adults of both sexes are better univariate predictors of normal heart mass than is body height. ${ }^{14}$ When matched for age and body surface area, however, normal heart weight was greater in men than in women and the correlations between heart weight and body surface area were better in men than in women. ${ }^{14}$ In contrast with the well established correlation between body surface area and heart mass, the relation between age and heart mass is somewhat controversial. In our study, it was shown that there are significant correlations between the body surface area and QRS duration (correlation coefficient $=0.396, \mathrm{p}<0.001$ ) as well as RMS40 (correlation coefficient $=-0 \cdot 159, \mathrm{p}$ $<0.025$ ), but not between body surface area and LAS40 (correlation coefficient $=0.034, p$ $>0 \cdot 25$ ). The significantly larger body surface area in normal men (mean $=1.93 \mathrm{~m}^{2}$ in men and $1.67 \mathrm{~m}^{2}$ in women), confirms that a normal man has on average a greater cardiac mass than a woman. This implies that the conduction of cardiac excitation and hence the QRS duration is longer. Of passing curiosity, the ratio $Q R S$ duration to body surface area had a mean value of 53.17 in women and 51.58 in men (two sample $t$ test for the mean $(95 \% \mathrm{CI})$ difference $1.59(-3.42$ to 0.23$) \mathrm{NS}$, $t=-1 \cdot 75, \mathrm{p}=0.086$, degrees of freedom $=$ 54) showing that QRS duration normalised by body surface area is independent of sex.

Current ESC/AHA/ACC recommended criteria $^{6}$ are not sex related and give only $85 \%$ specificity in men and $91 \%$ specificity in women in our apparently healthy population. Because the only parameter that was shown to have dependence on sex was QRS duration, the data of fig 1 were examined to select a cut off point giving $95 \%$ specificity. As a result, cut off values of $114 \mathrm{~ms}$ for men and $104 \mathrm{~ms}$ for women were chosen.
Clearly late potentials result from a long QRS duration that must form a part of any set of criteria. Table 4 shows that even with existing criteria, ${ }^{6}$ the combination of QRS duration with either LAS40 or RMS40 gives a very similar high specificity. Indeed in this normal population the correlation between LAS40 and RMS40 was high (correlation coefficient $=-0.658, p<0.001$ ). Current recommendations are to use any two of the three criteria of table 4 and this is clearly less specific. Nevertheless, to maintain a high sensitivity the retention of both LAS40 and RMS40 is suggested.

This leads to two main conclusions:

(1) If criteria for ventricular late potentials are not sex dependent, then to maintain high specificity they should be applied as followsQRS duration $>114 \mathrm{~ms}$ and either LAS40 $>38 \mathrm{~ms}$ or RMS $40<20 \mu \mathrm{V}$.

(2) If criteria for ventricular late potentials are sex dependent, and fig 1 clearly shows that the upper limit of QRS duration should be sex dependent, then it is recommended that ventricular late potentials $(40-250 \mathrm{~Hz})$ should be regarded as present when $a+(b$ or $c)$ below is true.

(a) QRS duration $>114$ ms (men); QRS duration >104 ms (women); (b) LAS40 >38 ms; (c) RMS40 $<20 \mu \mathrm{V}$.

This gives a specificity of $97 \%$ in men and $100 \%$ in women (table 4).

We thank S McLaughlin, $\mathrm{PhD}$ and J Watson, MSc for statistical advice.

1 Jarrett JR, Flowers NC. Signal-averaged electrocardiography: history, techniques, and clinical applications. graphy: history, techniques,

2 Simson MB. Use of signals in the terminal QRS complex to identify patients with ventricular tachycardia after to identify patients with ventricular tachycardia

3 Cripps TR, Counihan PJ, Frenneaux MP, Ward DE Camm AJ, McKenna WJ. Signal-averaged electrocardiography in hypertrophic cardiomyopathy. $f \mathrm{Am} \mathrm{Coll}$ graphy in hypertrophic

4 Flowers NC, Wylds AC. Ventricular late potentials in normal subjects. Herz 1988;13:1308-13.

5 Coto H, Maldonado C, Palakurthy P, Flowers NC. Late potentials in normal subjects and in patients with ventricular tachycardia unrelated to myocardial infarction. Am $\mathcal{F}$ Cardiol 1985;55:384-90.

6 Breithardt G (chairman), Cain ME, El-Sherif N, Flowers $\mathrm{N}$, Hombach V, Janse $M$, et al. Standards for analysis of ventricular late potentials using high resolution or signalaveraged electrocardiography. A statement by a Task Force Committee between the European Society of Cardiology, the American Heart Association and the American College of Cardiology. Eur Heart $\mathcal{f} 1991$; 12:473-80.

7 Macfarlane PW, Chen CY, Chiang BN. Comparison of the ECG in apparently healthy Chinese and Caucasians. Computers in Cardiology, IEEE Proceedings 1988:143-6.

8 Du Bois D, Du Bois EF. A formula to estimate the approximate surface area if height and weight be known. Arch Intern Med 1916;17:863-71.

9 Lander P, Albert DE, Berbari EJ. Spectrotemporal analysis of ventricular late potentials. F Electrocardiol 1990;23: of ventricul 108.

10 Kelen GJ, Henkin R, Starr A, et al. Spectral turbulence analysis of the signal-averaged electrocardiogram and its analysis of the signal-averaged electrocardiogram and its predictive accuracy of inducible sustained monomorphic

11 Engel TR, Pierce DL, Murphy SP. Variation in late potenEngel TR, Pierce DL, Murphy SP. Variation in late poten-
tials and the reproducibility of their measurement. Prog tials and the reproducibility of the
Cardiovasc Dis 1993;35:247-62.

12 Steinberg JS, Bigger JT Jr. Importance of the endpoint of noise reduction in analysis of the signal-averaged electrocardiogram. Am $\mathcal{f}$ Cardiol 1989;63:556-60.

13 Malik M, Odemuyiwa O, Poloniecki J, Kulakowski P, Farrell T, Staunton A, Camm AJ. Age-related normal values of signal-averaged electrocardiographic variables after acute myocardial infarction. Am f Cardiol 1991, 68:440-55.

4 Kitzman WD, Scholz DG, Hagen PT, Ilstrup DM, Edwards WD. Age-related changes in normal human hearts during the first 10 decades of life. Part II (Maturity): a quantitative anatomic study of 765 specimens from subjects 20-99 years old. Mayo Clin Proc 1988;63:137-46. 